\title{
The head morphology of Ascioplaga mimeta (Coleoptera: Archostemata) and the phylogeny of Archostemata
}

\author{
THOMAS HÖRNSCHEMEYER ${ }^{1}$, JÜRGEN GOEBBELS ${ }^{2}$, GERD WEIDEMANN ${ }^{2}$, CORNELIUS FABER $^{3}$ and AXEL HAASE ${ }^{3}$ \\ ${ }^{1}$ Universität Göttingen, Institut für Zoologie \& Anthropologie, Abteilung Morphologie \& Systematik, D-37073 Göttingen, Germany; \\ e-mail: thoerns@gwdg.de \\ ${ }^{2}$ Bundesanstalt für Materialforschung (BAM), Berlin, Germany \\ ${ }^{3}$ Physikalisches Institut, University of Würzburg, Germany
}

Keywords. Archostemata, Cupedidae, phylogeny, NMR-imaging, skeletomuscular system, micro X-ray computertomography, head morphology

\begin{abstract}
Internal and external features of the head of Ascioplaga mimeta (Coleoptera: Archostemata) were studied with micro $\mathrm{X}$-ray computertomography $(\mu \mathrm{CT})$ and nuclear magnetic resonance imaging (NMRI). These methods allowed the reconstruction of the entire internal anatomy from the only available fixed specimen. The mouthparts and their associated musculature are highly derived in many aspects. Their general configuration corresponds to that of Priacma serrata (the only other archostematan studied in comparable detail). However, the mandible-maxilla system of $A$. mimeta is built as a complex sorting apparatus and shows a distinct specialisation for a specific, but still unknown, food source. The phylogenetic analysis resulted in the identification of a new monophylum comprising the genera [Distocupes + (Adinolepis + Ascioplaga $)$ ]. The members of this taxon are restricted to the Australian zoogeographic region. The most prominent synapomorphies of these three genera are their derived mouthparts.
\end{abstract}

\section{INTRODUCTION}

Ascioplaga mimeta Neboiss, 1984 occurs in New Caledonia (a French island ca. $1400 \mathrm{~km}$ ENE of Brisbane, Australia) and is a member of the Cupedidae, one of six extant families of Archostemata. Archostemata is the sistergroup of all other Coleoptera (Hörnschemeyer, 1998; Beutel \& Haas, 2000; Caterino et al., 2002). Fossils of Coleoptera belonging to this taxon have been found in sediments as old as 250 Mio. years (Permian: Sackmarian; Labandeira, 1994). What makes the Archostemata especially interesting in terms of the evolution of the Coleoptera and of the evolution of the Holometabola is the fact that these Coleoptera obviously did not change significantly over millions of years. Comparing the external morphology of the fossils and of the extant species, one finds only few differences. Unfortunately, only three of the 42 known extant species are, at least partially, well studied. In terms of morphology the species best investigated is Priacma serrata LeConte, 1861. For this species the morphology of head, thorax and aedeagus and the flight behaviour (Edwards, 1953a, b; Atkins, 1958; Baehr, 1975; Hörnschemeyer et al., 2002) have been studied in detail. Another species that has attracted much effort is Micromalthus debilis LeConte, 1878. The peculiar life cycle of this species with its two different types of reproducing larval stages has been thoroughly investigated (Barber, 1913; Pringle, 1938; Scott, 1938, 1941; Kühne, 1972; Pollock \& Normark, 2002). Also the morphology of some of the larval stages of M. debilis (Beutel \& Hörnschemeyer, 2002a), and of Rhipsideigma raffrayi Neboiss, 1984 (Beutel \& Hörnschemeyer, 2002b) have been documented in detail. At least some of the larval stages are also known for Tenomerga cincerea (Say,
1831) (Snyder, 1913; Barber \& Ellis, 1920), Tenomerga mucida (Chevrolat, 1829) (Fukuda, 1938, 1939), Distocupes varians (Lea, 1902) (Neboiss, 1968), P. serrata (Ross \& Pothecary, 1970), and an unknown species of Omma (Lawrence, 1999). For all other species, including $A$. mimeta, almost no information beyond the original descriptions and subsequent descriptions of the aedeagi (Tamanuki, 1928; Vidal Sarmiento, 1969, Neboiss, 1984, 1989; Miyatake, 1985, 1986; Lawrence, 1999) is available. Published treatments of the biology of the archostematan species are even scarcer than that of their morphology. The host plants are known only for $T$. cinerea (Snyder, 1913), T. mucida (Fukuda, 1939), D. varians (Neboiss, 1968) and for M. debilis (Pollock \& Normark, 2002). As mentioned above, M. debilis also is the only species for which the complete life cycle is known.

Archostemata are most diverse in the Australian zoogeographic region. At present we know of thirteen species that occur there. Australia and South America are the only regions where Ommatidae and Cupedidae occur together. In the Australian region the Cupedidae are represented by nine species. One of these, Tenomerga kapnodes Neboiss, 1984, is restricted to New Guinea, while the other eight species belong to three genera which occur exclusively on the Australian mainland, on Tasmania or on New Caledonia. The distribution of these three genera (Distocupes, Adinolepis and Ascioplaga) leads to the question of whether they form a monophylum. If they do, the radiation of this monophylum must have started after the Australian continental plate had separated from Gondwana, i.e. in the Cretaceous (Torsvik \& Smethurst, 1999), meaning that the group would be comparatively 
young. Previous analyses of the phylogenetic relationships of the archostematan genera do not present information that enables us to answer this question. Either the necessary taxa were not investigated (Beutel \& Hörnschemeyer, 2002 a) or the positions of these three genera was not resolved unambiguously (Hörnschemeyer et al., 2002). Only now, that five specimen of Asciolaga mimeta are available for investigation, one with preserved soft tissues and four dry specimens, we can collect enough data to test the hypothesis that an Australian monophylum exists within the Cupedidae.

To gather as much information as possible from the one available fixed specimen of $A$. mimeta, we decided to use micro X-ray computed tomography $(\mu \mathrm{CT})$ and nuclear magnetic resonance imaging (NMRI) as non-invasive methods for this study.

\section{MATERIAL AND METHODS}

\section{Material}

Fixed specimens

Ascioplaga mimeta Neboiss, 1984, from New Caledonia $\left(21.585^{\circ} \mathrm{S}, 165.819^{\circ} \mathrm{E}\right)$, from the collection of Martin Hauser (Dept. of Entomology, University of Illinois).

Tenomerga cinerea Say, 1831, from the eastern United States, collected and donated by Warren E. Steiner (Smithsonian Institution, Washington D.C.).

Cupes capitatus Fabricius, 1801, from the eastern United States, collected and donated by Warren E. Steiner (Smithsonian Institution, Washington D.C.).

Distocupes varians (Lea, 1902), from Australia, donated by John F. Lawrence (Australian National Insect Collection, Australia).

Dried specimens from museum collections

Adinolepis mathesonae Neboiss, 1960, from eastern Australia, Australian National Insect Collection, Australia; National Museum Victoria, Australia.

Adinolepis youanga Neboiss, 1960, from eastern Australia, Australian National Insect Collection, Australia.

Ascioplaga mimeta Neboiss, 1984, from New Caledonia, private collection of Martin Hauser (Dept. of Entomology, University of Illinois).

Distocupes varians (Lea, 1902), from Australia, Australian National Insect Collection, Australia.

The dry specimens were used to compare the external morphology of the head capsule and its appendages.

\section{Methods}

The only available specimen of Ascioplaga mimeta with soft tissue preservation had been placed after collection into $70 \%$ ethanol. From there it was transferred to an alcoholic Bouin's solution (= Duboscq-Brasil) (Romeis, 1989: 97) for two days for additional fixation. Subsequently, it was stored in $80 \%$ ethanol.

Prior to nuclear magnetic resonance imaging (NMRI) the intact specimen was immersed in $100 \%$ aqua bi-dest. Data were acquired on a $750 \mathrm{MHz}$ widebore Magnet system (Bruker, Rheinstetten) at the Institute of Physics, Univ. of Würzburg. A 5 mm-microscopy probe inside a gradient system with $1 \mathrm{~T} / \mathrm{m}$ maximum gradient strength was used to record a threedimensional dataset using a spin echo method $(\mathrm{TE} / \mathrm{TR}=18 / 500$ ms). A matrix of $360 \times 180 \times 180$ data points was acquired over a field of view of $9.0 \times 4.5 \times 4.5 \mathrm{~mm}^{3}$ to result in a spatial resolution of $25 \times 25 \times 25 \mu \mathrm{m}^{3}$ (per volume pixel = voxel) in a total scan time of exactly $18 \mathrm{~h}$. Images were reconstructed after zero- filling to a $512 \times 256 \times 256$ matrix, resulting in a resolution of $18 \mu \mathrm{m}$ per pixel.

For the micro X-ray computed tomography $(\mu \mathrm{CT})$ investigation the head and prothorax were separated from the rest of the body and dried at the critical point in a Balzer CPD 030 Critical Point Dryer. The X-ray tomography was accomplished with the 3D-CT II X-ray tomograph at the Federal Institute for Materials Research (BAM), Berlin (Goebbels et al., 2002). Data were acquired at $40 \mathrm{kV}, 200 \mu \mathrm{A}$, resulting in a spatial resolution of $2.5 \mu \mathrm{m}$ per point in three dimensions. Data acquisition took about $7 \mathrm{~h}$.

Sections were calculated from both 3D-datasets (256 longitudinal sections from the NMR data and 867 cross sections from the $\mu \mathrm{CT}$ data) that could then be used for analysis and 3Dreconstructions.

The software packages NOESYS (Research Systems) and Amira 2.3 (TGS) were used to handle the data and for preparation of the figures.

Due to the methods used for collecting the image-data and for the image-reconstruction, the individual muscles do not appear as solid structures but instead appear to consist of a number of thin muscle fibers, which represents the real structure of the muscles.

The muscles were named and numbered according to Kéler (1963).

Samples for scanning electron microscopy were transferred to $100 \%$ ethanol and subsequently dried with a Balzers CPD030 critical point dryer. The dry specimens were sputter-coated with gold (Balzers SCD050 Sputter Coater) and viewed and photographed in a Leo 438VP scanning electron microscope (SEM).

The phylogenetic analysis was done with PAUP* version 4.0b10 (Swofford, 2001). The data matrix (see appendix) is based on a matrix used by Hörnschemeyer et al. (2002) extended by two characters concerning the larval proventriculus and a muscle between the gular ridges (Beutel \& Hörnschemeyer, 2002a). The characters concerning the scales, the protuberances, the mandible and the maxillary palps of the adult head were re-coded to fit the new observations and a character describing the state of the antennal muscles was added. Sialis (Neuroperida: Megaloptera) and Trachypachus (Coleoptera: Trachypachidae) were used as outgroups. The outgroup taxa were treated like the ingroup taxa in the analysis (simultaneous analysis, Nixon \& Carpenter, 1993). The analysis was done with the branch-and-bound algorithm (bandb) with all parameters set to the standard values. The robustness of the results was tested with a bootstrap analysis with 1000 replicates and by calculating the Bremer-support values (Bremer, 1988, 1994) with AutoDecay 5.03 (Eriksson, 2001). The character evolution was analysed using accelerated (ACCTRAN) as well as delayed (DELTRAN) character transformation (Wiley et al., 1991).

\section{RESULTS}

\section{Morphology}

\section{Head capsule (Fig. 1)}

The size of Ascioplaga mimeta varies from $9.6 \mathrm{~mm}$ to $14.33 \mathrm{~mm}$ total length $(\mathrm{n}=5)$. The head is about as long as it is wide and nearly twice as wide than it is high. The head surface is densely covered with scales (Fig. 1A-C), completely hiding the cuticle from view. The color of the scales ranges from dark brown to white. The cuticle underneath is black. The postgenal area is prolonged and delimited from the anterior part of the head by an abrupt constriction. This narrow posterior area of the head forms a ball-and-socket joint with the prothorax. The exposed 


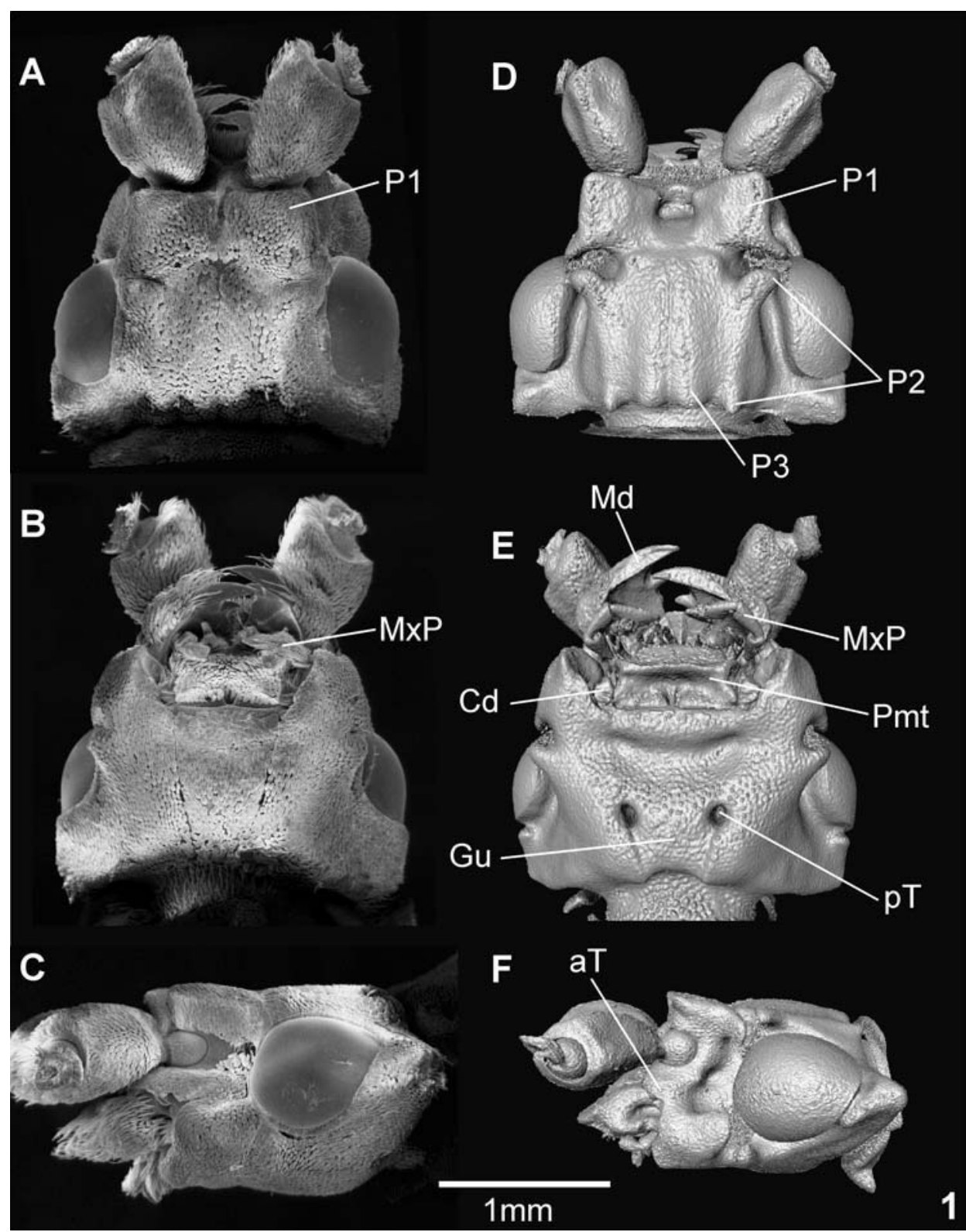

Fig. 1. Head of Ascioplaga mimeta. A-C SEM images, D-F Images reconstructed from $\mu \mathrm{CT}$ data showing the surface of the head without the scales. A, D - dorsal view, B, E - ventral view, C, F - left lateral view. aT = anterior tentorial pit, $\mathrm{Cd}=\mathrm{cardo}, \mathrm{Gu}=$ gula, $\mathrm{Md}=$ mandible, $\mathrm{MxP}=$ maxillary palpus, $\mathrm{P} 1=$ protuberance above antennal insertion, $\mathrm{P} 2$ = protuberance above the eye, $\mathrm{P} 3=$ median posterior protuberance of the head, $\mathrm{Pmt}=$ prementum, $\mathrm{pT}=$ posterior tentorial pit.

part of the head is slightly shorter than it is wide (length/width $=0.88$ ). The submental region separating the genae becomes narrower towards the posterior margin of the head. It is completely integrated into the ventral wall of the head capsule. The eyes are nearly spherical with a truncated posterior margin. The postocular genal region is just over half as long as the diameter of an eye. The antennae are inserted dorsally, above the dorsal joints of the mandibles. Antennal furrows are absent. One pair of prominent protuberances is present posterio-dorsally to the antennal bases (Fig. 1: P1). The dense cover of scales hides some protuberances from view that become visible only in the X-ray data or after removal of the scales (Fig. 1D-F): a pair of lateral elongated bulges, which reach from just behind the anterior margins of the eyes to the constriction of the head (Fig. 1: P2). The anterior ends of theses bulges are extended into anterior-laterally directed protuberances. The posterior ends of the bulges form very small protuberances. A third pair of small protuberances (Fig. 1: P3) is present on both sides of the median line at the posterior margin of the visible part of the head. The tentorium is greatly reduced. Posterior and dorsal tentorial arms form a pair of thin continuous bars running from the posterior tentorial pits dorso-craniad to just below and in front of the cerebrum. There the Musculus tentorioscapalis lateralis (M3) originates from the dorsal tentorial arm (Fig. 5, 8: dTa). The anterior tentorial pits are very small and lie on the ventral rim of the antennal insertion (Fig. 1F: aT). Anterior tentorial arms could not be identi- 

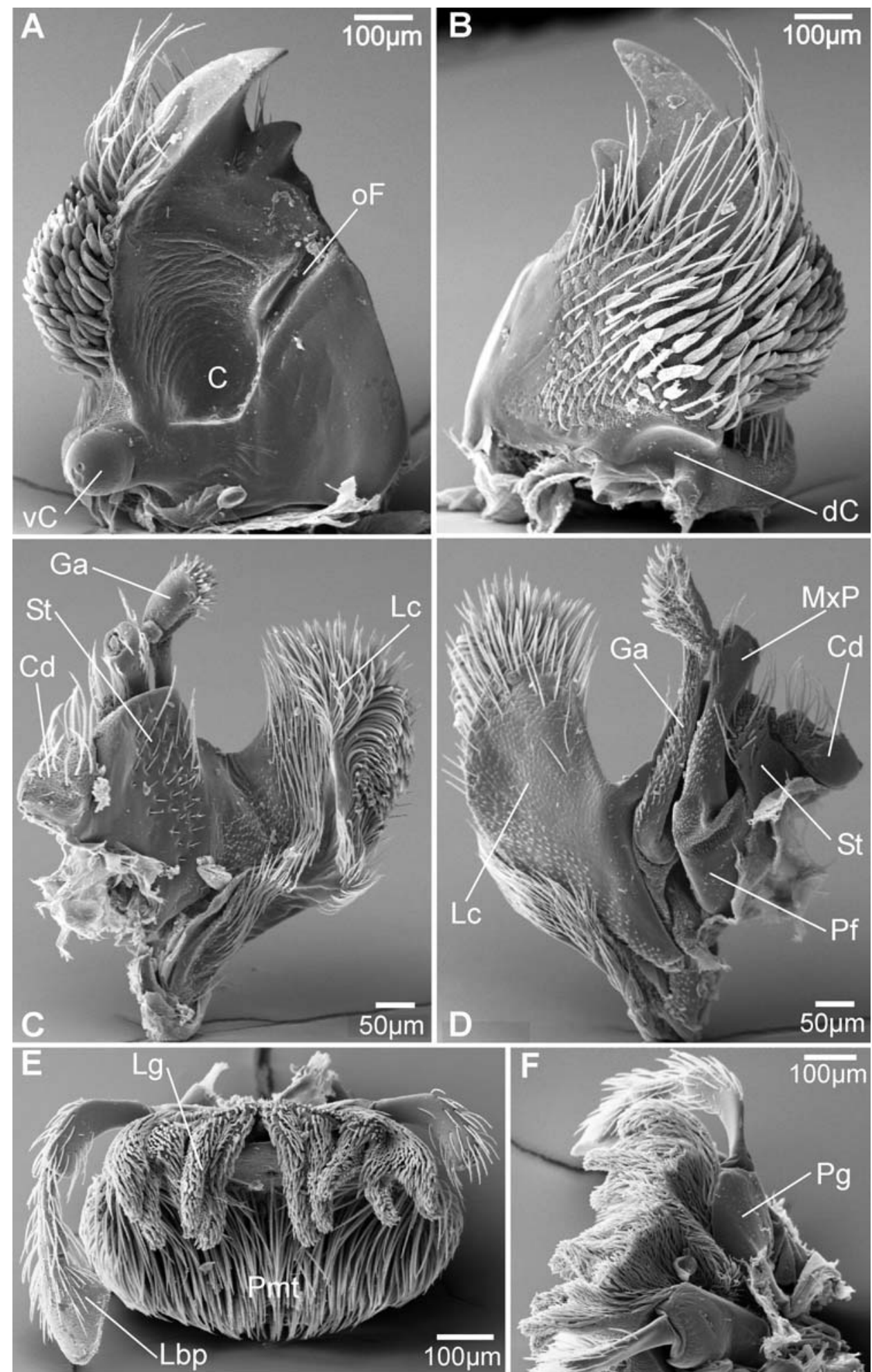

2

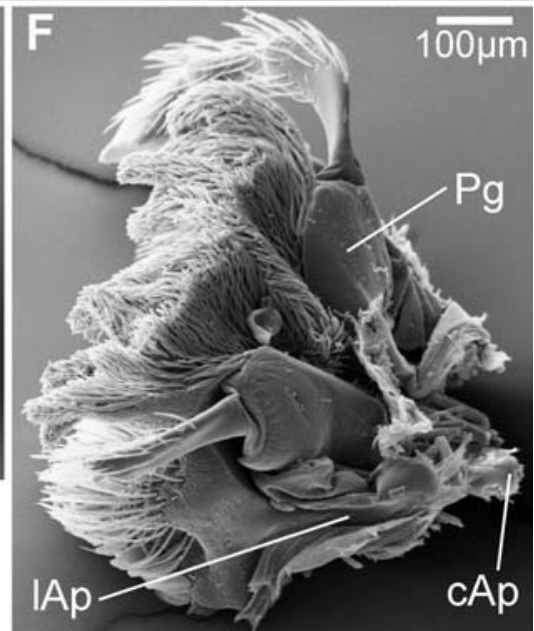

Fig. 2. SEM images of mouthparts of Ascioplaga mimeta (Coleoptera: Archostemata). A Ventral view of right mandible. B Dorsal view of right mandible. $C$ Ventral view of right maxilla without cardo. D Dorsal view of right maxilla without cardo. The apical segments of the maxillary palpus have been removed. E Frontal view of labium. F Left dorso-lateral view of labium. The apical segments of the left labial palpus have been removed. $\mathrm{C}=$ cavity, $\mathrm{cAp}=$ central apodeme of prementum, $\mathrm{Cd}=\mathrm{cardo}, \mathrm{dC}=\mathrm{dorsal}$ articular cavity of mandible, $\mathrm{Ga}=$ galea, $\mathrm{AAp}=$ lateral apodeme of prementum, $\mathrm{Lbp}=$ labial palpus, $\mathrm{Lbr}=\mathrm{labrum}, \mathrm{Lc}=\mathrm{lacinia}, \mathrm{Lg}=$ ligula, $\mathrm{MxP}=$ maxillary palpus, $\mathrm{oF}=$ oblique furrow, $\mathrm{oR}=$ oblique ridge, $\mathrm{Pf}=$ palpifer, $\mathrm{Pg}=$ palpiger, $\mathrm{Pmt}=$ prementum, $\mathrm{PmtAp}=$ central apodem of prementum, $\mathrm{St}=$ stipes, $\mathrm{vC}=$ ventral condylus of mandible. 


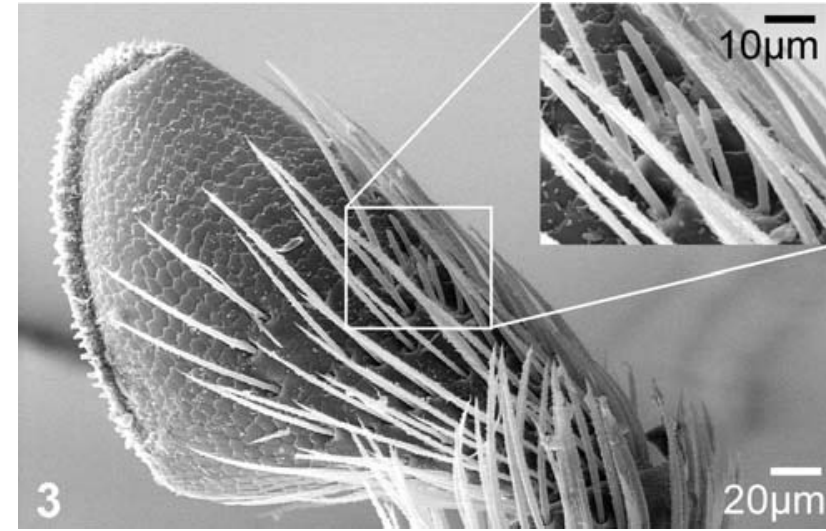

Fig. 3. SEM image of apical segment of right maxillary palpus of Ascioplaga mimeta in dorsal view with apical field of sensilla to the left and inset showing detail of dorso-lateral sensorial patch.

fied. The gula is trapezoidal in shape and moderately broad.

\section{Labrum (Figs 4, 8)}

The labrum is moveably connected to the head-capsule. It is about one sixth as wide as the head. The dorsal surface is covered with anteriorly inclined long hairs.

Musculus (= M.) labroepipharyngalis (M7, not figured). This muscle is represented by just a few muscle fibers. They originate medially on the dorsal wall of the labrum and insert medially on the ventral wall (epipharynx). The muscle pair works as levator of the epipharynx.

M. frontoepipharyngalis (M9, not figured). A pair of short, slender muscles originating on the frons between the antennal insertions and inserting on the tormae of the epipharynx. They work as the depressor of the labrum.

Antenna (Figs 1, 5, 6, 8)

The 11-segmented antennae are inserted dorsally. Their insertions are slightly less than one scapus diameter apart. Antennomeres 1 (= scapus) to 4 are covered with light brown to beige colored scales, hiding the cuticle from view. Antennomeres $5 \& 6$ are covered at least dorsally with scales, the remaining surface is densely set with slender setae but the dark cuticle is still visible. Antennomeres 7 to 11 bear only these slender setae. All antennomeres, with exception of scapus and pedicellus, are elongate and slightly flattened dorso-ventrally. The scapus is two times as long as the pedicellus and distinctly wider. The pedicellus and the following antennomeres are of equal width. The antennomeres 3 and 5 to 10 are 2.4 times as long as the scapus. Antennomere 4 is 1.9 times as long as the scapus. The apical antennomere (11) is 3.3 times as long as the scapus.

The antenna is moved by four muscles associated with the scapus and two muscles that are attached to the pedicellus (Figs 5, 6, 8).

M. tentorioscapalis anterior (Figs 5, 8: M1). The origin of M. t. anterior lies with a wide base on the vertex. It inserts via a thin tendon medio-ventrally on the

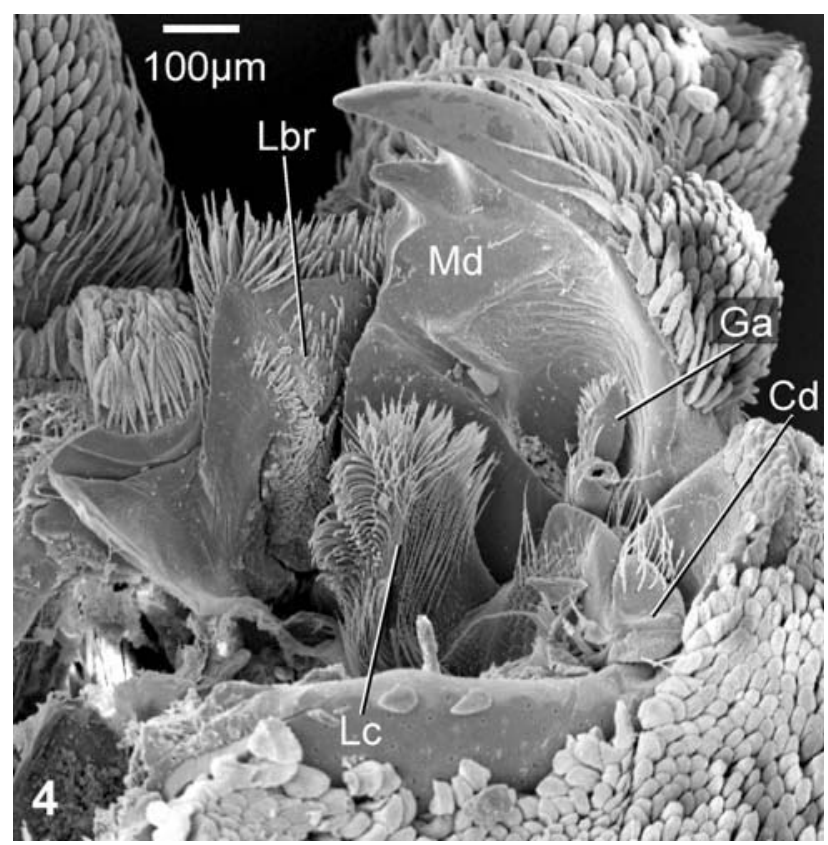

Fig. 4. SEM image of left mouthparts of Ascioplaga mimeta in situ. Ventral view. Labium and right side mouthparts have been removed. $\mathrm{Cd}=$ cardo, $\mathrm{Ga}=$ galea, $\mathrm{Lbr}=$ labrum, $\mathrm{Lc}=$ lacinia, $\mathrm{Md}=$ mandible.

base of the scapus and functions as the depressor and together with M2 as protractor of the antenna.

M. tentorioscapalis posterior (Figs 6, 8: M2). This muscle has its origin on the vertex anterior to $M$. ts. anterior. It inserts with a short tendon medio-dorsally on the base of the scapus. M. ts. posterior works as levator and together with M. t. anterior as protractor of the antenna.

M. tentorioscapalis lateralis (Figs 5, 8: M3) originates on the anterior end of the dorsal tentorial arm. It inserts on the scapus via the same tendon as M. t. anterior.

M. tentorioscapalis medialis (Figs 6, 8: M4) originates between M. t. anterior and M. t. posterior on the vertex, just laterad of the median ridge. It inserts dorsolaterally on the basal rim of the scapus. The function of this muscle is to move the antenna backward and upward.

M. scapopedicellaris lateralis (Fig. 8: M5). Originates on the posterior dorsal wall near the base of the scapus and inserts dorsally at the base of the pedicellus. It moves the flagellum backward and upward.

M. scapopedicellaris medialis (Figs 5, 8: M6). This muscle is composed of two parts. One part originates on the median wall at the base of the scapus and inserts medio-ventrally on the base of the pedicellus. The second part originates with a wide base on the median wall of the scapus above part one. It inserts on the pedicellus mediodorsally of part one. Both parts together move the flagellum anteriorly.

\section{Mandible (Figs 1, 2A, B)}

The mandible is about one third as long as the head capsule. The apex and one distinct tooth are arranged in a horizontal row along the mesal cutting edge. Mola and lacinia mobilis are absent. A deep cavity connected to the 

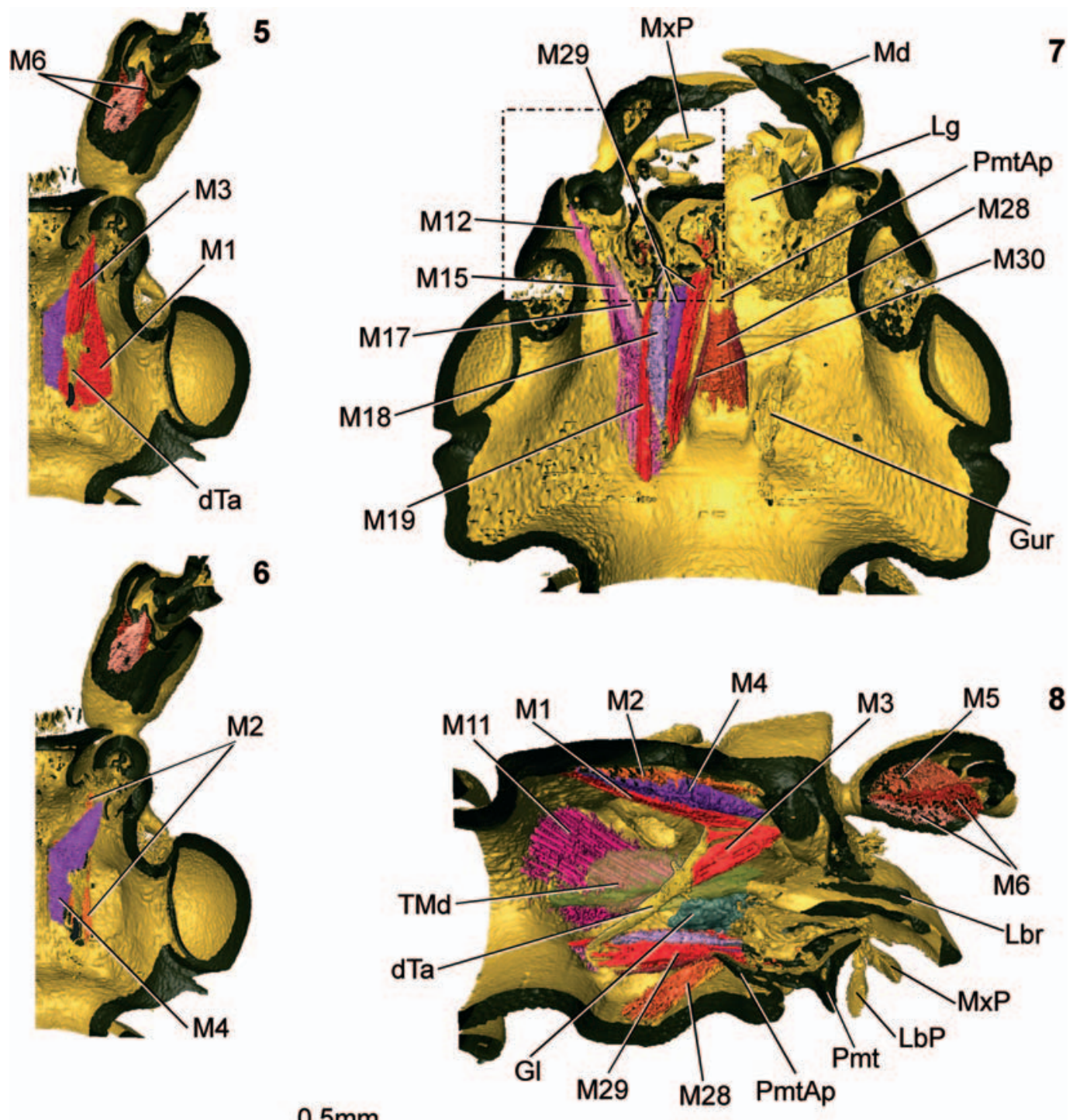

\section{$0.5 \mathrm{~mm}$}

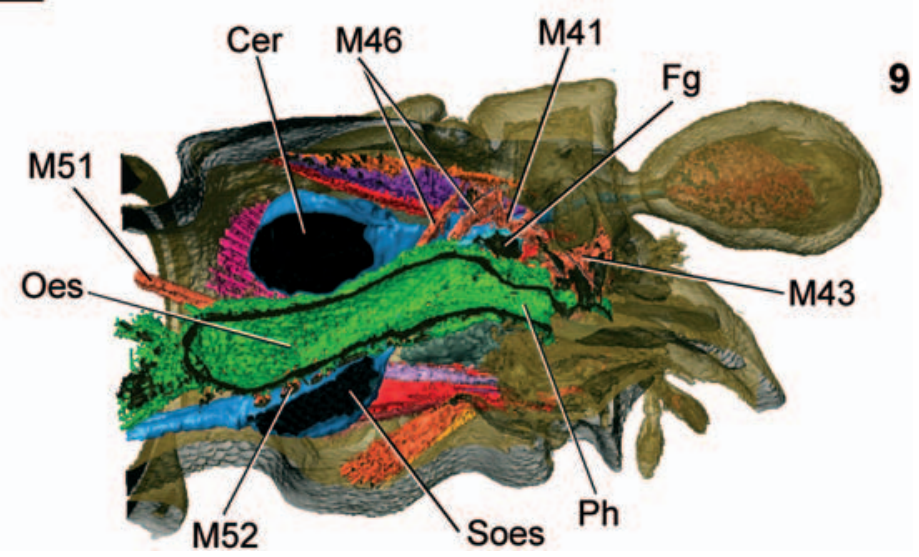

Figs 5-9. 5, 6 - images of 3D-reconstructions from $\mu \mathrm{CT}$ data of the head of Ascioplaga mimeta. 5 - ventral view of dorsal area of the head showing antennal musculature. 6 - same as in Fig. 5, but M1 and M3 removed to reveal M2 and M4. 7 - image of 3Dreconstruction from $\mu \mathrm{CT}$ data of the head of Ascioplaga mimeta. Dorsal view of ventral area of the head showing musculature of mouthparts. In the area marked with the dash-dot-line the cutting plane has been set somewhat deeper to reveal the apical portions of the muscles. $\mathrm{Gur}=$ gular ridge, $\mathrm{Lg}=$ ligula, $\mathrm{Md}=$ mandible, $\mathrm{MxP}=$ maxillary palpus, $\mathrm{PmtAp}=$ central apodem of prementum. $8,9-$ images of 3D-reconstructions from $\mu \mathrm{CT}$ data of the head of Ascioplaga mimeta. 8 - medial view of the virtual sagittal section through the head. 9 - same as in Fig. 8 but cuticle transparent and with pharynx, oesophagus and nervous system in place. Cer = cerebrum, $\mathrm{dTa}=$ dorsal tentorial arm, $\mathrm{Fg}=$ frontal ganglion, $\mathrm{Gl}=$ gland, $\mathrm{Lbp}=$ labial palpus, $\mathrm{Lbr}=$ labrum, $\mathrm{MxP}=$ maxillary palpus, Oes $=$ oesophagus, $\mathrm{Pmt}=$ prementum, PmtAp $=$ central apodem of prementum, Soes $=$ suboesophageal ganglion, $\mathrm{TMd}=$ tendonplate of mandible. For terminology of muscles see Results: Morphology. 
cutting edge via a deep, oblique furrow is located in the medio-lateral area of the ventral surface. The medioposterior part of the ventral surface is smooth and slightly concave. In vivo the club of the galea reaches into the cavity and the lacinia lies on the smooth, concave surface. The anterior half of the dorsal surface is smooth without hairs or scales. The lateral surface and the basal half of the dorsal surface are sculptured with small tubercles like most of the body parts. Laterally, it is densely covered with scales, which become more slender, longer and hairlike towards the apex of the mandible.

M. craniomandibularis internus (Fig. 8: M11). This muscle is the adductor of the mandible and the largest head muscle. It is connected to the mandible by a large, forked tendon plate. The muscle is composed of a dorsal and a ventral portion. The dorsal portion originates on the dorso-lateral and posterior area of the head from just behind the eye (circumocular ridge) to the posterolateral corner of the head. It inserts on the dorsal surface of the tendon plate, which is connected via a broad base to the posteriomedian part of the mandible. The ventral portion of M11 originates on the latero-ventral and posterior wall of the head. Laterodorsally it extends to just below the dorsal portion of M11. The ventral portion inserts on the ventral surface of the tendon-plate.

M. craniomandibularis externus (Fig. 7: M12). The muscle is distinctly smaller than M. c. internus. It originates with a wide base on the ventral wall of the head laterad of the gular ridge from about the middle of the eye to the constriction of the head. It inserts via a long tendon at the lateral posterior corner of the mandible, just above the ventral joint. M12 is the abductor of the mandible.

Maxilla (Figs 1, 2C, D, 3, 4)

The cardo is small. Its frontal surface is sculptured with some very small tubercles and bears a few long setae. The lateral surface is smooth. The apodeme for attachment of the cranial cardinal extensor is short and Y-shaped. The stipes is undevided and more than twice as large as the cardo. The surface of the stipes is smooth for the most part, with a few slender setae on the ventral surface. The maxillary palpus is four-segmented and inserts on a palpifer which is inserted latero-dorsally on the stipes. All segments are about equal in length. Palpomeres 1 to 3 are cylindrical and about two times as long as wide. The apical palpomere is wedge shaped. Palpomeres 2 and 3 are covered with long strong setae, whereas only four to six setae are present on the dorsal and ventral side of the distal end of palpomere 1. Two fields of sensilla are present on the apical palpomere (Fig. 3): an apical field, with many short sensilla basiconica (the length of which is less than twice the width) and an area at the midpoint of the dorso-lateral side of the palpomere with six characteristic sensilla, which are about eight times longer than wide. In addition to these two sensillar fields the basal two thirds of the apical palpomere bear numerous long, slender setae. The galea is composed of a slender stalk, about as long as palpomere I, and a widened club with robust, wide setae on its oral side. The lacinia is as long as the galea and spade-shaped. The ventral surface is covered with two different types of long setae. On the surface adjacent to the mouth-opening there are mainly roundtipped, cylindrical setae, on the rest of the surface they are tapered and have a few low ridges.

M. craniocardinalis externus (Fig. 7: M15). A muscle with its origin on the head capsule exactly in front and laterad of the base of the posterior tentorial arm. Inserts on the distal tip of the apodeme of the cardo. Musculus craniocardinalis internus (M16) is missing as in all Coleoptera (Beutel, pers. com.).

M. tentoriocardinalis (Fig. 7: M17). This muscle has its origin on the base of the posterior tentorial arm above M. craniocardinalis externus. The insertion lies on the proximal tip of the cardo apodeme.

M. tentoriostipitalis (Fig. 7: M18). The origin of this muscle lies on the ridge of the posterior tentorial arm and the insertion in the posterior median area of the stipes. M. tentoriostipitalis is an adductor of the stipes. It probably also moves the cardo.

M. craniolacinialis (Fig. 7: M19) is long and slender. It has its origin on the head capsule at the posterior constriction above the gular ridge. The muscle inserts on the median posterior corner of the lacinia.

There are no internal muscles of the lacinia [M. stipitolacinialis $(\mathrm{M} 20)]$ or the galea [M. stipitogalealis (M21)].

M. stipitopalpalis externus / internus (M22 / M23, not figured). Only one muscle is present at the base of the palp. Considering its insertion on the external margin of the palpal base, homology with M. s. externus appears likely. The origin of the muscle is on the posterior ventral wall of the stipes.

The distal muscles of the maxillary palp, M. palpopalpalis tertius (M26, not figured) and M. p. quartus (M27, not figured), are present. M. p. maxillae primus (M24) and M. p. secundus (M25) are missing.

\section{Labium (Figs 1, 2E, F, 8)}

The submentum is fused to the head capsule. Its posterior margin is marked by the posterior tentorial pits. The mentum is reduced to a membrane connecting prementum and submentum. The prementum is a sclerite of complex form. It is rectangular and shield-like in frontal view and has a prominent central apodeme in its lower half. This apodeme is marked externally by a deep pit. The lateral margins of the prementum are bent inwards and prolonged as lateral apodemes. The frontal outer surface is covered with long hairs whereas the ventral surface is densely covered with scales. All areas of the outer surface are sculptured with low protuberances like the rest of the head. The prementum functions as a lid that completely covers the mouth and the ligula (i.e., the fused glossae and paraglossae), and the galeae and laciniae when they are retracted. The palps are three-segmented and insert on large, soft and smooth palpigers. The apex of the first palpomere, the distal half of the second and the complete, wedge-shaped, apical palpomere bear a few long setae. The sensilla on the apical palpomere are concentrated in two areas. They are short in the apical area, whereas six long, apically rounded sensilla are arranged in a shallow 
pit in the dorso-lateral area. The apex of the ligula is differentiated into 10 digitiform appendages. The dorsal and ventral surfaces of the ligula are covered with short, wide setae.

M. submentopraementalis (Figs 7, 8: M28). A pair of short, strong muscles that originate with a broad base left and right of the median line of the submentum between the posterior tentorial arms. The muscles insert side by side on the apex of the central apodeme of the prementum and function as retractors of the prementum.

M. tentoriopraementalis inferior (Figs 7, 8: M29). A pair of strong muscles, originating with a wide base on the median sides of the posterior tentorial arms and the gular ridges. They have a wide insertion on the lateral apodemes of the prementum and mediad thereof. M29 probably is the antagonist of M28 and M30, pulling the prementum downwards.

M. tentoriopraementalis superior (Fig. 7: M30). A pair of slender muscles. They originate on the median sides of the gula ridges below and behind M29. The muscles pass over the apex of the central apodeme of the prementum and insert in the middle of its dorsal surface close to the base of the ligula.

M. praementoparaglossalis / praementoglossalis (M31 / M32, not figured). In the ligula there are a number of muscle fibers running from the middle of the prementum anterio-laterad to the base of the digitiform appendages of the ligula. These muscles work as retractors of the ligula.

M. praementopalpalis externus (M34, not figured). The muscle originates on the dorso-lateral surface of the central apodeme of the prementum and inserts on the lateral base of the first palpomere.

The internal muscles of the labial palpus M. palpopalpalis labii primus (M35, not figured) and M. palpopalpalis labii secundus (M36, not figured) are both present.

Hypopharynx

The hypopharynx is not developed as a distinct and separate element. It is fused to the labium, forming a functional unit with it.

M. frontohypopharyngalis (Fig. 9: M41). A pair of fairly strong muscles that originate in the central part of the verticofrontal area. They insert by means of tendons on the fulturae and function as retractor muscles of the mouth angles.

M. tentoriohypopharyngalis (M42) is absent.

\section{Cibarium}

The cibarium is a simple, laterally open preoral cavity.

M. clypeopalatalis (Fig. 9: M43). A pair of short muscles originating from the epistomal area, or more precisely, from the median inner walls of the antennal insertions and inserting dorsolaterally on the cibarium. The muscles have equally wide origins and insertions and run nearly horizontally between these two points. The muscle pair works as dilator of the cibarium.

\section{Pharynx (Fig. 9)}

The pharynx is fairly wide and approximately round in cross section. The anterior pharynx has a set of longitu- dinal muscles and relatively strong circular muscles, especially in the area below the frontal ganglion.

M. clypeobuccalis (M44, not figured). This pair of short muscles originates on the epistomal area, between the antennal insertions. They insert side by side on the dorsal wall of the pharynx between and just behind $\mathrm{M}$. clypeopalatalis. M44 is a dilator of the anterior pharynx.

M. frontobuccalis anterior (M45, not figured). The origin of this thin muscle lies on the clypeo-frontal border in front of $\mathrm{M}$. frontohypopharyngalis. From there it extends mediad of $M$. frontohypopharyngalis to the latero-dorsal wall of the pharynx where it inserts closely beside and behind the frontal ganglion.

M. frontobuccalis posterior (Fig. 9: M46). This muscle is of similar size as M. frontohypopharyngalis. The origin lies laterad and anterior of $\mathrm{M}$. frontohypopharyngalis on the frons-vertex border. From here, M. f. posterior extends laterad of $\mathrm{M}$. frontohypopharyngalis to the insertion on the latero-dorsal wall of the pharynx in front of the cerebrum.

M. verticopharyngalis (Fig. 9: M51). A pair of long, slender muscles that originate dorso-laterally on the posterior area of the head capsule. The muscles insert dorsolaterally at the end of the pharynx posterior to the cerebrum. Together with M. tentoriopharyngalis this muscle pair works as dilator of the posterior pharynx.

M. tentoriopharyngalis (Fig. 9: M52). This series of thin muscles originates on the gular ridge laterad of the suboesophageal ganglion and from the lateral parts of the gula. They insert ventro-laterally on the posterior pharynx.

\section{Postoccipital region (Fig. 10)}

Seven muscles could be identified that are associated with the movements of the head.

M. praephragmapostoccipitalis medialis (Fig. 10B, C: M55) [M 1 of Baehr (1975)]. This muscle runs from the praephragma to the mediodorsal margin of the postocciput.

M. pronotopostoccipitalis medialis (M57, not figured) [M 6 of Baehr (1975)]. A very slender muscle, consisting of just a few muscle fibers, that originates in the anteriolateral corner of the pronotum and inserts laterad and ventrad of M. pronotocervicalis (M60) on the border of the postocciput.

M. profurcatentorialis (M58) [M 5 of Baehr (1975)] / M. profurcacervicalis (M59) [M 8 of Baehr (1975)] (Fig. 10B: M58/M59). Only one pair of muscles is present that runs from the profurca to the ventromedian area of the head. A part of the muscle inserts inside the head on the gular ridge and the remainder of the muscle inserts on the border of the postocciput. This suggests that the muscle is the result of a fusion of muscles M58 and M59.

M. pronotocervicalis (Fig. 10C: M60) [M 2 of Baehr (1975)]. A fan-shaped muscle with the origin on the medio-lateral part of the pronotum. It runs between M55 and M70 to the dorso-lateral margin of the postocciput laterad of M55. The insertion of this muscle is significantly wider than the origin. 

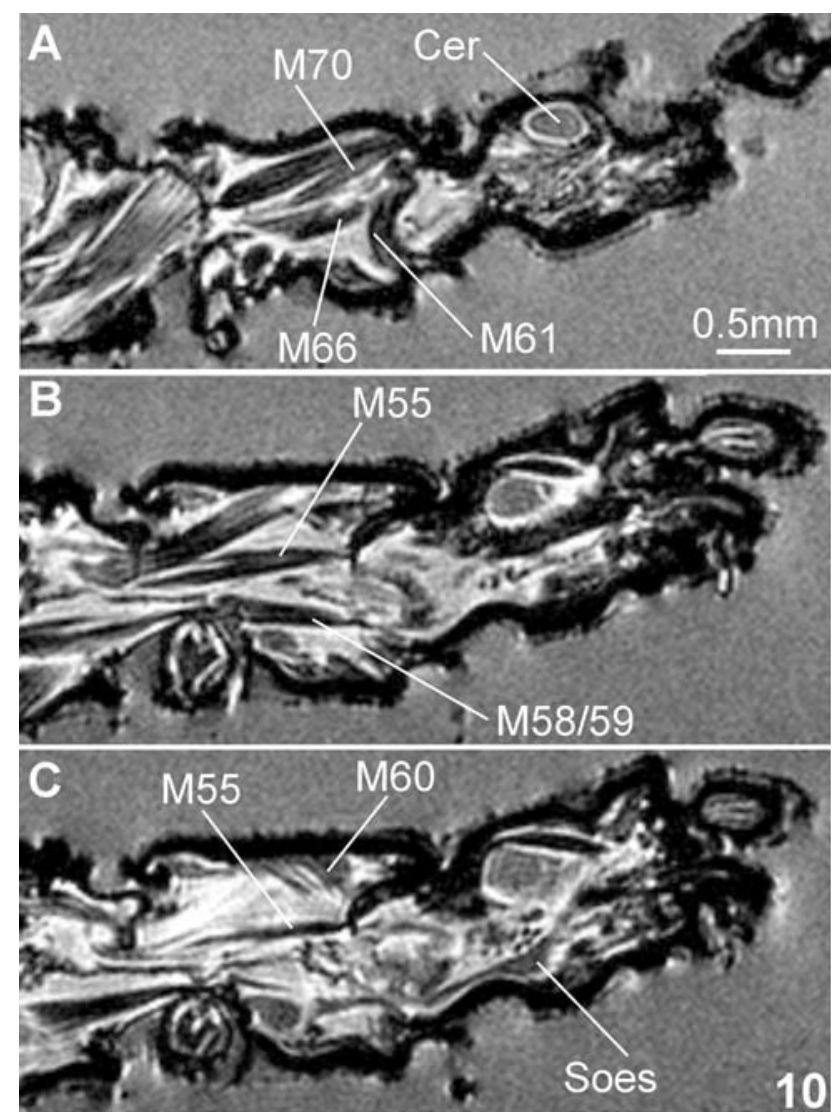

Fig. 10. Longitudinal sections of head and prothorax of Ascioplaga mimeta reconstructed from NMR-data. Section A is the most lateral one, section $\mathrm{C}$ lies nearly in the median line of the body, and section B lies between A and C. Cer = cerebrum, Soes $=$ suboesophageal ganglion. For terminology of muscles see Results: Morphology.

M. cervicopostoccipitalis (Fig. 10A: M61) [M 9 of Baehr (1975)]. The slender muscle originates in the anterolateral area of the sternum, immediately behind the neck membrane. It inserts on the dorso-lateral margin of the postocciput ventrad of M57.

M. propleuracervicalis (M64) [M 7 of Baehr (1975)] is missing.

M. profurcacervicalis (Fig. 10A: M66) [M 10 of Baehr (1975)]. A strong muscle that originates on the profurca laterad of M58 / M59 and inserts on the lateral margin of the postocciput below M61.

M. conjunctiva-antecostalis (Fig. 10A: M70) [M 3 of Baehr (1975)]. Originates far lateral on the praephragma and runs laterad of M60 to the insertion far laterad and dorsad on the neck membrane.

Cerebrum and suboesophageal ganglion (Fig. 9)

The cerebrum is comparatively small in relation to the head and located between the compound eyes. The suboesophageal ganglion is fairly slender and laterally enclosed by the gular ridges.

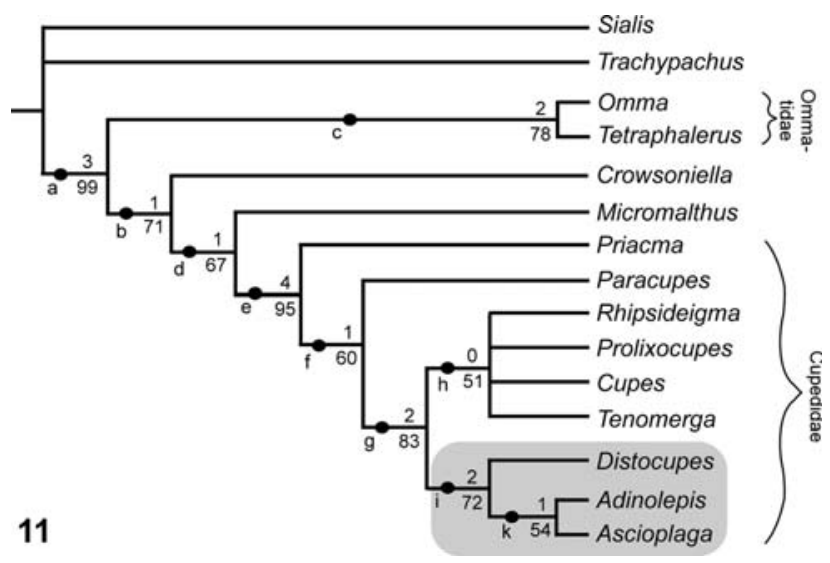

Fig. 11. Phylogenetic relationships of the genera of the Archostemata, Australian monophylum with grey background. Strict consensus tree. The Bremer-support values are given above the branches. Below the branches are the bootstrap values for 1000 replicates. Selected autapomorphies are as follows (for further characters see text): a cuticular scales present (see discussion) (1.1); constricted neck present (2.1); tentorium strongly reduced, bridge absent (7.1); prementum enlarged and plate-like, with central apodeme (13.1); larval ligula sclerotized and wedge-shaped (30.1); segment $\mathrm{X}$ of larval abdomen not visible externally (39.1); b see discussion; c dorso-lateral sensorial patch on apical maxillary palpomeres in deep cavity (14.3); propleuro-mesepisternal locking mechanism with mesepisternal condyle and propleural socket (19.2); d abdominal sterna tegular or overlapping (21.1); e galea differentiated in stalk and club (12.1); ligula as pair of undevided lobes (15.1); penultimate tarsomere distinctly bilobed (20.1); f antennae inserted dorsally on head capsule (9.1); g lobes of ligula strongly divided (15.3); prosternum with grooves for reception of tarsomeres (16.1); $h$ protuberances above eyes with large anterior and small posterior tip (4.5); prothorax of larva broader than following segments (33.1); i mandible with deep cavity and oblique furrow (11.2); k prementum shield-like (13.3).

\section{Glands (Fig. 8)}

A pair of glands is present in the posterior labiohypopharyngeal region. The openings of the glands lie at the bases of the maxillae.

\section{Phylogenetic analysis (Fig. 11)}

One of the species of Archostemata, Sikhotealinia zhiltzovae Lafer, 1996, the only extant representative of Jurodidae, was not included in the analysis. The only known specimen of this species is the holotype, which was not available for investigation. Therefore, most of the necessary data are not available for this species.

The data-matrix used for the analysis contains 15 taxa, including two outgroup taxa, and 42 characters (see appendix). Characters 1 to 21 refer to the adult morphology; characters 21 to 42 describe the larval morphology and the habitat of the larvae. All the characters were equally weighted and treated as unordered. The branchand-bound search resulted in 21 equally parsimonious trees with a length of 85 steps each (consistency index $(\mathrm{CI})=0.84$; re-scaled $\mathrm{CI}(\mathrm{RC})=0.73)$. The strict consensus tree is shown in Fig. 11. 

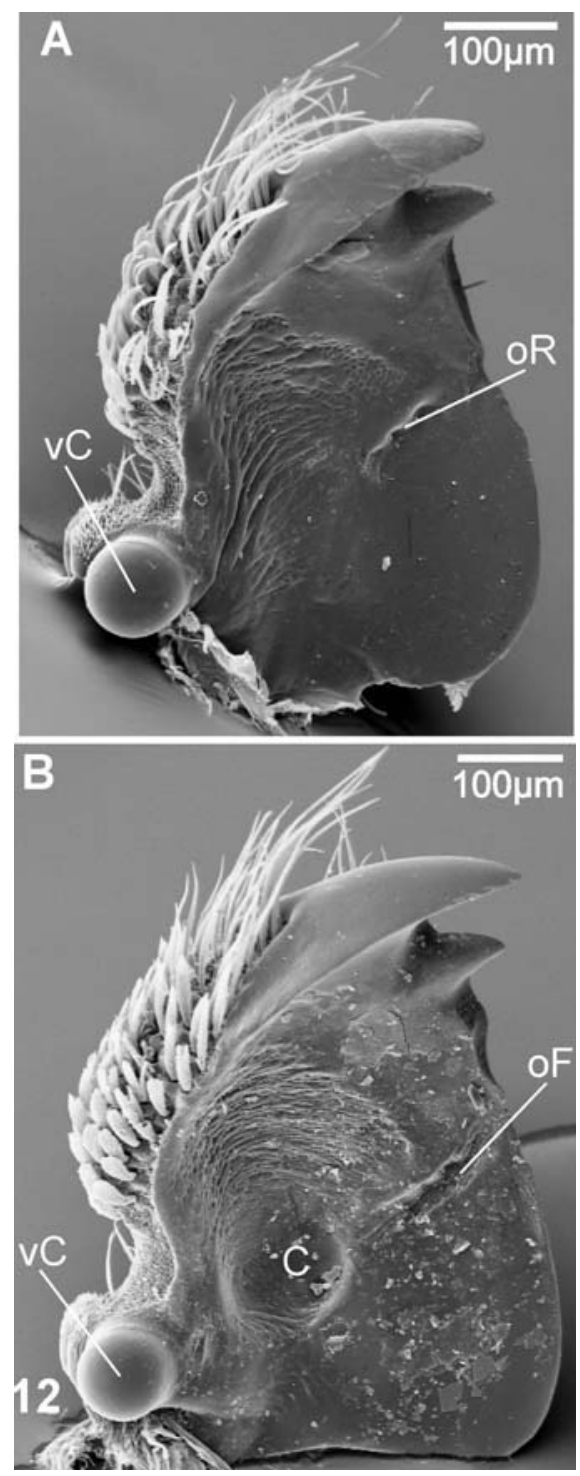

Fig. 12. SEM images of ventral surfaces of right mandibles. A Tenomerga cinerea. $\mathrm{B}$ Distocupes varians. $\mathrm{C}=$ cavity, $\mathrm{o} \mathrm{R}=$ oblique ridge, $\mathrm{oF}=$ oblique furrow, $\mathrm{vC}=$ ventral condylus of mandible.

Unless otherwise noted, the following list gives only the unambiguous autapomorphies for monophyletic groups that occur in the tree for accelerated (ACCTRAN) as well as for delayed (DELTRAN) character transformation (Fig. 11):

Archostemata (Fig. 11: a): constricted neck present (2.1); tentorium strongly reduced, bridge absent (7.1); prementum enlarged and plate-like, with central apodem (13.1); frontal suture of later instars indistinct or absent (25.1); distal part of mandible with three apices (28.1); ligula sclerotized, enlarged and wedge-shaped (30.1); mentum and submentum fused (31.1); abdominal segments I-III of later instars longer than thorax (32.1); tergal ampullae present (34.1); segment $\mathrm{X}$ not visible externally (39.1).

Ommatidae (Fig. 11: c): dorso-lateral sensorial patch on apical maxillary palpomeres in deep cavity (14.3); propleuro-mesepisternal locking mechanism with mesepisternal condyle and propleural socket (19.2).

Crowsoniella + (Micromalthus + Cupedidae) (Fig. 11: b): galea missing (12.2) (implies reversal in Cupedidae, see discussion).

Micromalthus + Cupedidae (Fig. 11: d): abdominal sterna tegular or overlapping (21.1).

Cupedidae (Fig. 11: e): galea differentiated into a narrow proximal stalk and a rounded, pubescent club (12.1); ligula represented by a pair of undivided lobes (15.1); prosternal process reaching beyond hind margin of procoxae (17.1); propleuro-mesepisternal locking mechanism with propleural condyl and mesepisternal socket (19.1); penultimate tarsomere distinctly bilobed (20.1).

Cupedidae without Priacma (Fig. 11: f): antennae inserted dorsally on head capsule (9.1).

Cupedidae without Priacma and Paracupes (Fig. 11: g): distinct, isolated protuberances above eyes present (4.1); ligula with lobes strongly divided (15.3); prosternal grooves for tarsomeres present (16.1); anteromedian pit of mesoventrite for reception of prosternal process present (18.1).

Distocupes + (Adinolepis + Ascioplaga) (Fig. 11: i): cuticular scales with longitudinal and transverse ridges present (1.2); ventral surface of mandible with deep cavity and oblique furrow (Fig. 12B) (11.2); dorso-lateral sensorial patch on apical maxillary palpomeres indistinct pit or without pit and with maximally six sensilla (14.2).

Adinolepis + Ascioplaga (Fig. 11: k): prementum shield-like (13.3).

Rhipsideigma + Prolixocupes + Cupes + Tenomerga (Fig. 11: h): protuberances above eyes (Fig. 1D: P2) with anterior tip large ( $\geq 1 / 2$ of height of eye) and posterior tip blunt and small to absent (4.5); protuberances between P2, on both sides of the median line of the head (Fig. 1D: P3) distinct (5.1); larval prothorax broader than following segments (33.1); lateral longitudinal bulge of larval abdominal segments I-VII present (36.1).

\section{DISCUSSION}

\section{Morphology and function}

A number of features of the head of Ascioplaga mimeta are characteristic of Archostemata in general. The tuberculate structure of the cuticle, the scales, and the protuberances above the antennal insertions are present in all species of Cupedidae and Ommatidae. Also the connection of the head to the prothorax by means of a ball-andsocket joint is very similar to what is found e.g. in Priacma serrata (Hörnschemeyer et al., 2002). Another typical archostematan structure is the modified labium. The prementum forms a lid that covers the ligula, galea, lacinia and the mouth opening. The muscles of the prementum are attached to a central apodeme. All these structures are unique to Archostemata.

In regard to the internal anatomy, only $P$. serrata is available for detailed comparison (Hörnschemeyer et al., 2002). There are several conspicuous differences between $A$. mimeta and $P$. serrata. In $A$. mimeta the tentorial arms are much longer than in $P$. serrata and a fourth antennal 
muscle (M3) is attached to their dorsal anterior tip. The same condition is also found in Cupes capitatus Fabricius, 1801 (T. Hörnschemeyer, pers. observ.). The presence of four antennal muscles is unusual. In most adult insects there is a maximum of three muscles connected to the scapus. According to Kéler (1963), the presence of a fourth muscle is only known for some endopterygote larvae and in a few hemimetabolous insects (i.e. Gryllotalpa). Nevertheless, also in Lytta vesicatoria (Coleoptera: Polyphaga; Schneider, 1981) and in some Hymenoptera (Xyelidae, R.G. Beutel, pers. commun.) four extrinsic antennal muscles are present.

Since $P$. serrata and most Endopterygota have three muscles at the scapus, we have to assume that four antennal muscles evolved independently in Polyphaga, in Xyelidae and in Cupedidae. Consequently the presence of four extrinsic antennal muscles is an autapomorphy of a sub-taxon of Cupedidae. Because information about the antennal muscles is only available for the aforementioned three cupedid species, we can not determine the composition of this sub-taxon exactly. But since $C$. capitatus and $A$. mimeta both have four extrinsic antennal muscles and are members of monophyla which are sistergroups (Fig. 11), we assume that, at least in Cupedidae without Priacma and Paracupes four antennal muscles are present.

The mandible, in relation to the head length, is much shorter in A. mimeta than in P. serrata. Moreover, its ventral surface is structured in a very characteristic way (Figs $2 \mathrm{~A}, 4)$. The deep cavity in the lateral half exactly fits with the galea. Similar structures of the ventral surface of the mandible are present in Distocupes varians (Fig. 12B) and in species of Adinolepis ( $\mathrm{T}$. Hörnschemeyer, pers. observ.), whereas in the other Cupedidae (Fig. 12A) the mandible is much simpler. Another difference between $A$. mimeta and $P$. serrata is the structure of the stipes (Fig. 2C, D). In P. serrata and in most other Coleoptera (Williams, 1938) the stipes is differentiated into a proximal basistipes and a distal mediostipes. In A. mimeta the stipes is undivided and quite large. As a whole, the system consisting of mandible, galea, lacinia and ligula (Figs 2,4) is a complex sorting mechanism for food that mainly consists of small particles. The nature and origin of these particles could not be determined from the remains found in the cavity of the mandible. The content of the thoracic intestine was also investigated but did not reveal any identifiable particles. Nevertheless, pollen grains or spores fit well into the size range of particles that could be manipulated with these structures. These complex and highly specialized mouthparts and the welldeveloped intestine strongly suggest that the adults of $A$. mimeta really do feed.

In $P$. serrata the Musculus craniolacinialis (M19) has a quite unusual origin at the base of the posterior tentorial arm. In most other insects and in all investigated Coleoptera (Kéler, 1963; Hörnschemeyer et al., 2002) this muscle originates in the posterolateral region of the head capsule. A. mimeta seems to be plesiomorphic in this respect, because M19 has its origin ventrally on the head capsule at the beginning of the neck-constriction (Fig. 7), i.e., relatively close to the position that is found in other insects. This implies that the unusual origin of M19 in $P$. serrata probably is an autapomorphy of this species.

The presence of a ligula retractor (M. praementoparaglossalis / praementoglossalis (M31 / M32)) in A. mimeta is remarkable, because in all other investigated Coleoptera there are no muscles inserted on the ligula (Kéler, 1963; Beutel \& Haas, 2000). This is in accordance with the results of Baehr (1975), who found that the thoracic musculature of Priacma serrata comprises more muscles than that of other Coleoptera. The fact that species of Archostemata have muscles that otherwise are known, for example, from hemimetabolous insects but not from other Coleoptera can be interpreted as an additional indication of the basal position of Archostemata in the system of Coleoptera. This supports the results of Hörnschemeyer (1998), Beutel \& Haas (2000) and Caterino et al. (2002).

\section{Phylogeny (Fig. 11)}

The basal relationships of Archostemata are reconstructed very similarly in the present study as well as by Beutel \& Hörnschemeyer (2002a) and by Hörnschemeyer et al. (2002). In all analyses the Cupedidae and the Ommatidae are well supported as monophyla with a sistergroup relationship.

The Ommatidae are characterized by two unambiguous autapomorphies, the deep cavity for the dorso-lateral sensorial patch on the apical maxillary palpomeres (14.3) and the propleuro-mesepisternal locking mechanism with the condyle on the mesepisternum and the socket on the propleura (19.2). These characters are unique in Archostemata and they support the monophylum well, even under the condition of the bootstrap analysis. The variable from of the anterior head-tubercles (P1, character 3 ) in the species of Omma and Tetraphalerus has no significant influence on the reconstruction of the phylogeny. The modifications of this structure obviously took place independently in both genera. It may well be related to the biology of these species, whose larva are suspected to develop in plant roots (Vidal Sarmiento, 1969). If the imagines have to dig in the ground to reach the larval substrate for the deposition of the eggs or to free themselves after hatching, then the reduction of head tubercles might be an advantage. This interpretation is supported by the distinctly wedge shaped heads of Omma and Tetraphalerus species.

The Cupedidae are still better supported by autapomorphies than the Ommatidae. Only the position of Micromalthus debilis and Crowsoniella relicta is still problematic. Neither Beutel \& Hörnschemeyer (2002a) nor Hörnschemeyer et al. (2002) or the present study could determine the phylogenetic position of Micromalthus debilis and Crowsoniella relicta satisfactorily. In the results of Beutel \& Hörnschemeyer (2002a) and Hörnschemeyer et al. (2002) the position of these two species is mainly supported by larval characters. The position of $M$. debilis and C. relicta in the tree in Fig. 11 is most similar to the results of Hörnschemeyer et al. (2002). Even though the position of both these species on the cla- 
dogram seems to be reasonably stable in terms of Bremersupport and bootstrap values, it is not well supported by synapomorphies. This might be attributed to the large number of autapomorphic characters of both these species, which make it difficult to identify synapomorphies of these species in common with other taxa. For example, the only autapomorphy of the clade [Crowsoniella + (Micromalthus + Cupedidae) (Fig. 11: b) that is persistent under delayed (DELTRAN) and accelerated (ACCTRAN) character transformation is the absence of the galea (12.2). In Micromalthus and Crowsoniella the galea is absent, but Cupedidae have a clubbed galea (12.1). One can safely assume that the galea was lost twice (probably due to miniaturisation), once in Micromalthus, once in Crowsoniella and that the clubbed galea of Cupedidae was derived from a galea, as it is present in Ommatidae. This pathway is one step longer than the assumption that the galea was lost once and then reevolved, but it seems more probable that such an appendage was modified once and lost twice, especially in such highly modified species. The other characters that support the position of Micromalthus and Crowsoniella are all from larval morphology. This gives only a weak support, because the larva of Crowsoniella is still unknown and the arrangement of these characters varies heavily with the optimisation method (ACCTRAN or DELTRAN). In the light of this uncertain character situation we regard the position of $M$. debilis and $C$. relicta as still unresolved and see them in a basal polytomy with Ommatidae and Cupedidae at the base of the Archostemata.

A similar problem, also related to Micromalthus and Crowsoniella, is the interpretation of the evolution of the scales within the Archostemata (character 1). The result of the cladistic analysis is that scales developed twice independently: (i) in the stemline of Ommatidae (Fig. 11: c) and (ii) in the stemline of Cupedidae (Fig. 11: e). This character evolution is stable under ACCTRAN and DELTRAN optimisation and obviously is related to the fact that Micromalthus as well as Crowsoniella do not have scales. Nevertheless, it is equally parsimonious to assume that the stem species of Archostemata had scales and that $M$. debilis and $C$. relicta lost them twice independently, which we think to be the more plausible hypothesis for the evolution of this character.

An essential result of this study is the identification of a monophylum comprising the taxa Distocupes, Adinolepis and Ascioplaga (Fig. 11: i). With one exception, i.e. the transverse ridges on the scales, all synapomorphies of these three taxa are related to the mouthparts. Here, the most prominent character is the mandible with its complex ventral structures (Figs 2A, 4), compared to the simple, nearly smooth ventral surface of the mandible of other Cupedidae (Fig. 12A). These structures are the results of an adaptation to a special food source, which seems to have been the starting point for the radiation of this taxon. Since all of its members are restricted to the Australian region, this radiation seems to be a rather recent event that started after the separation of the Austra- lian continental plate from Gondwana, i.e. in the Cretaceous (Torsvik \& Smethurst 1999). The position of Ascioplaga as sistergroup of Adinolepis (Fig. 11: k) is supported by the transverse and shield-like prementum. In the other Archostemata it usually is at least as broad as long.

These relationships were not found in previous analyses (Beutel \& Hörnschemeyer, 2002a; Hörnschemeyer et al., 2002). Beutel \& Hörnschemeyer (2002a) could not identify the Australian monophylum, because they had no specimens of Ascioplaga or Adinolepis available for their investigation. Hörnschemeyer et al. (2002) included data for these two genera in their analysis. The relationships that they reconstructed within the Cupedidae are quite similar to our results. They also identified Ascioplaga and Adinolepis as sistergroups but the position of Distocupes could not be resolved unambiguously. As we know now, the reason is that important synapomorphies of Adinolepis, Ascioplaga and Distocupes are present in the structures of the mouthparts, which could not be studied by Hörnschemeyer et al. (2002). The inclusion of mouthpart characters increased the resolution and the stability of the reconstructed phylogeny significantly.

\section{Methods}

The data presented in this study where collected using micro X-ray tomography, NMR tomography and scanning electron microscopy. Since only one specimen of $A$. mimeta with preserved soft tissues was available, other means of investigation (e.g. hand preparation, serial sectioning) would likely have produced a less comprehensive and less precise analysis.

The best data were gathered with micro X-ray tomography. The quality of the data delivered by this method improved considerably in comparison to its first application for the investigation of the anatomy of an insect (Hörnschemeyer et al., 2002). The image contrast is higher and the spatial resolution at $2.5 \times 2.5 \times 2.5 \mu^{3}$ per point in three dimensions is about twice as high as in the previous datasets. This study demonstrates that micro $\mathrm{X}$-ray tomography is already a very useful tool for the study of the soft tissues of small to medium sized invertebrates. Future improvement of the data acquisition and the development of contrasting methods will further extend the possibilities of this method for the study of invertebrate anatomy.

NMR tomography, with a spatial resolution of $25 \times 25$ $\times 25 \mu^{3}$, yielded valuable information supplementary to the data from the X-ray tomography. The NMR images allowed verification of larger structures in the X-ray images and to collect information about the muscles that move the head. Due to the coarse resolution, our NMR data gave useful information only for larger muscles. It is to be expected that for further applications with smaller specimens resolutions below $10 \times 10 \times 10 \mu \mathrm{m}^{3}$ can be achieved. Thus, the excellent tissue contrast of NMRI can facilitate morphological studies.

The non-invasive character of the applied tomography methods made it possible to prevent greater damage to the only available specimen. Although the specimen suffered 
slightly from the removal of the right-side mouthparts, it is still essentially intact and remains available for further investigations.

ACKNOWLEDGEMENTS. The authors wish to thank the following persons for making material available for investigation: We are very grateful to M. Hauser, University of Illinois, for donating one alcohol preserved specimen of $A$. mimeta from New Caledonia for our studies. J.F. Lawrence and T. Weir, CSIRO, Australia; D.V. Brown, Nat. Hist. Mus. Los Angeles, USA; A.F. Newton, Field Mus., Chicago, USA; O. Jäger, Staatl. Mus. Tierkunde, Dresden, Germany; M. Schmitt, Museum Alexander Koenig, Bonn, Germany; M. Uhlig, Museum für Naturkunde, Berlin, Germany. Many thanks also to G. Tröster, and S. Wedmann, Göttingen, Germany, to R.G. Beutel, Jena, Germany, Darren A. Pollock, Portales, USA and to an anonymous reviewer for their comments on the manuscript. T. Hörnschemeyer wants to thank R. Willmann, Inst. f. Zoologie \& Anthropologie, Göttingen, Germany for the general support of his work. The $750 \mathrm{MHz}$ NMR spectrometer is funded by the Deutsche Forschungsgemeinschaft (DFG) grant Ha1232/13 to A. Haase, Würzburg, Germany.

\section{REFERENCES}

AtKins M.D. 1958: Observations on the flight, wing movements and wing structure of male Priacma serrata. Can. Entomol. 90: $339-347$.

BAEHR M. 1975: Skelett und Muskulatur des Thorax von Priacma serrata LeConte (Col.: Cupedidae). Z. Morph. Ökol. Tiere 81: 55-101.

BARBER G.W. \& Ellis W.O. 1920: The beetles of the family Cupedidae of America, north of Mexico. J. N. Y. Entomol. Soc. 28: 197-209.

BARBER H.S. 1913: The remarkable life-history of a new family (Micromalthidae) of beetles. P. Biol. Soc. Wash. 26: 185-190.

Beutel R.G. \& HaAs F. 2000: Phylogenetic relationships of the suborders of Coleoptera (Insecta). Cladistics 16: 102-141.

Beutel R.G. \& Hörnschemeyer T. 2002a: Larval morphology and systematic position of Micromalthus debilis LeConte, 1878 (Coleoptera, Micromalthidae). Syst. Entomol. 27: 169-190.

Beutel R.G. \& Hörnschemeyer T. 2002b: Description of the larva of Rhipsideigma raffrayi (Coleoptera, Archostemata), with phylogenetic and functional implications. Eur. J. Entomol. 99: 53-66.

Caterino M.S., Shull V.L., Hammond P.M. \& Vogler A.P. 2002: Basal relationships of Coleoptera inferred from $18 \mathrm{~S}$ rDNA sequences. Zool. Scripta 31: 41-49.

BREMER K. 1988: The limits of amino acid sequence data in angiosperm phylogenetic reconstruction. Evolution 42: 795-803.

Bremer K. 1994: Branch support and tree stability. Cladistics 10: $295-304$.

EDWARDS J.G. 1953a: The morphology of the male terminalia of beetles belonging to the genus Priacma (Cupesidae). Bull. Inst. R. Sci. Nat. Belgique 29: 1-8.

EDWARDS J.G. 1953b: The peculiar clasping mechanisms of the phallus of males of Priacma (Cupesidae, or Cupedidae). Coleopt. Bull. 7: 17-20.

ERIKSSON T. 2001: AutoDecay ver. 5.0. Bergius Foundation, Royal Swedish Academy of Sciences, Stockholm, (program distributed by the author).

FUKUDA A. 1938: Description of the larva and pupa of Cupes clathratus. Trans. Nat. Hist. Soc. Formosa (Taihoku) 28: 390-393.
Fukuda A. 1939: On the larva of Cupes clathratus. Trans. Nat. Hist. Soc. Formosa (Taihoku) 29: 75-82.

Goebbels J., Weidemann G., Dittrich R., Mangler M. \& TomandL G. 2002: Functionally graded porosity in ceramics analysis with high resolution computed tomography. In: Singh J.P. (ed): Innovative Processing and Synthesis of Ceramics, Glasses, and Composites V. Proceedings of the 2001 Annual Meeting and Exposition of The American Ceramic Society, Indianapolis, April 22-25, 2001. Ceramic. Trans. 129: 113-124.

HöRnSCHEMEYeR T. 1998: Morphologie und Evolution des Flügelgelenks der Coleoptera und Neuropterida. Bonn. Zool. Monogr. 43: $126 \mathrm{~S}$.

Hörnschemeyer T., Beutel R.G. \& Pasop F. 2002: Head structures of Priacma serrata LeConte (Coleptera, Archostemata) inferred from X-ray tomography. J. Morphol. 252: 298-314.

KÉLER S.V. 1963: Entomologisches Wörterbuch. Akademie Verlag, Berlin, 744 pp.

KüHNE H. 1972: Entwicklungsablauf und -stadien von Micromalthus debilis LeConte (Col., Micromalthidae) aus einer Laboratoriums-Population. Z. Angew. Entomol. 72: 157-168.

LABANDEIRA C.C. 1994: A compendium of fossil insect families. Milwaukee Publ. Mus. Contr. Biol. Geol. 88: 1-71.

Lawrence J.F. 1999: The Australian Ommatidae (Coleoptera: Archostemata): new species, larva and discussion of relationships. Invertebr. Taxon. 13: 369-390.

MiyataKe M. 1985: Notes on the genus Tenomerga of Japan (Coleoptera: Cupedidae) Trans. Shikoku Entomol. Soc. 17: 21-26.

Miyatake M. 1986: A new species of the genus Tenomerga (Coleoptera, Cupedidae) from Yakushima Island, southwest Japan. In Ueno S.I. (ed.): Entomological Papers Presented to Yoshihiko Kurosawa on the Occasion of his Retirement. Coleopterists' Association of Japan, Tokyo, pp. 111-114.

Neboiss A. 1968: Larva and pupa of Cupes varians Lea, and some observations on its biology (Coleoptera: Cupedidae). Mem. Nat. Mus. Victoria 28: 17-19.

Neboiss A. 1984: Reclassification of Cupes Fabricius (s. lat.), with descriptions of new genera and species (Cupedidae: Coleoptera). Syst. Entomol. 9: 443-477.

Neboiss A. 1989: New species of Archostemata (Coleoptera, Ommatidae, Cupedidae). Rev. Fr. Entomol. (N.S.) 11: 109-115.

Nixon K.C. \& CARPenter J.M. 1993: On outgroups. Cladistics 9: 413-426.

Pollock D.A. \& Normark B.B. 2002: The life cycle of Micromalthus debilis LeConte (Coleoptera: Archostemata: Micromalthidae): historical review and evolutionary perspective. $J$. Zool. Syst. Evol. Res. 40: 105-112.

Pringle J.A. 1938: A contribution to the knowledge of Micromalthus debilis LeC. (Coleoptera). Trans. R. Entomol. Soc. London 87: 271-287.

RomeIs B. 1989: Mikroskopische Technik. 17. Aufl. Urban und Schwarzenber, München, Wien, Baltimore, $697 \mathrm{pp}$.

Ross D.A. \& Pothecary D.D. 1970: Notes on adults, eggs, and first-instar larvae of Priacma serrata (Coleoptera: Cupedidae). Can. Entomol. 102: 346-348.

SCHNEIDER W. 1981: Zur Morphologie der Imago des Ölkäfers Lytta vesicatoria (Coleoptera: Meloidae). Entomol. Gen. 7: 69-87.

ScotT A.C. 1938: Paedogenesis in the Coleoptera. Z. Morph. Ökol. Tiere 33: 633-653.

Sсотт A.C. 1941: Reversal of sex production in Micromalthus. Biol. Bull. 81: 420-431. 
SNYDER T.E. 1913: Record of the rearing of Cupes concolor Westw. (Coleoptera). Proc. Entomol. Soc. Wash. 15: 30-31.

Swofford D.L. 2001: PAUP* - Phylogeny Analysis Using Parsimony and Other Methods. Sinauer Associates, Sunderland.

TAMANUKI K. 1928: A taxonomic study of the Japanese Cupedidae. Zool. Mag. (Tokyo) 40: 242-254.

TORSVIK T.H. \& SMETHURST M.A. 1999: Plate tectonic modelling; virtual reality with GMAP. Comput. Geosci. 25: 395-402.

VIDAL SARMIENTo J.A. 1969: El sistema reproductor masculino y organos de copulation en Cupesidae (Coleoptera - Archostemata). Rev. Soc. Entomol. Argentina 31: 43-48.

Wiley E.O., Siegel-Causey D., Brooks D.R. \& FunK V.A. 1991: The Compleat Cladist. The University of Kansas Museum of Natural History Special Publication No. 19. University of Kansas, Lawrence, $158 \mathrm{pp}$.

Williams I.W. 1938: The comparative morphology of the mouth-parts of Coleoptera treated from the standpoint of phylogeny. J.N.Y. Entomol. Soc. 46: 245-289.

Received September 27, 2005; revised and accepted December 12, 2005

\section{APPENDIX - LIST OF CHARACTERS}

\section{Adults, general body}

1 - Cuticular scales: (0) absent (1) present with longitudinal ridges only (2) with longitudinal \& transverse ridges

Adults, head:

2 - Constricted neck: (0) absent (1) present

3 - Protuberances P1 (Fig. 1D), above antennal base: (0) absent (1) distinct (2) small

4 - Protuberances P2 (Fig. 1D) above eyes: (0) absent (1) anterior tip small, acute and upright, $(<1 / 3$ of height of eye), without a posterior tip or bulge (2) anterior tip absent, posterior tip acute and upright (3) anterior and posterior tips small and horizontal (4) one large blunt bulging structure reaching from the anterior corner of eye to the posterior margin of visible part of head (5) anterior tip large ( $\geq 1 / 2$ of height of eye), posterior tip blunt and small or absent (6) one anterior (blunt or acute) and one posterior blunt bulge of similar size or posterior one smaller

5 - Protuberances P3 (Fig. 1D), between P2, on both sides of the median line of the head: (0) absent (1) distinct (2) fused with $\mathrm{P} 2$

6 - Antennal muscle M. tentorioscapalis lateralis (M3): (0) absent (1) present
7 - Tentorium: (0) well developed, with bridge (1) strongly reduced, bridge absent

8 - Labrum: (0) free, connected with clypeus by membrane (1) indistinctly separated from clypeus (2) fused with head capsule

9 - Location of antennal insertion on head capsule: (0) lateral (1) dorsal

10 - Shape of mandible: (0) compact, curved with acute teeth arranged in horizontal row (1) narrow, crescent-shaped without additional teeth (2) elongated with rounded teeth (3) teeth arranged vertically (4) atrophied

11 - Ventral surface of mandible: (0) smooth (1) with oblique ridge (Fig. 12A) (2) with deep cavity and oblique furrow (Fig. 12B) (3) different

12 - Galea: (0) basal part about as broad as proximal part (1) divided into a narrow proximal stalk and a rounded, pubescent club (2) missing

13 - Prementum: (0) not enlarged, not plate-like (1) enlarged, plate-like, with median apodeme (2) broad at its base, with long median projection between labial palps (3) shield-like (4) reduced, very small

14 - Dorso-lateral sensorial patch on apical maxillary palpomeres: (0) absent (1) shallow but distinct pit, with more than six sensilla (2) no or indistinct pit, with maximally six sensilla (3) deep cavity (4) large flat field, dominating the palpomere (5) digitiform sensilla, longitudinally embeded into the cuticula

15 - Ligula: (0) small and simple or absent (1) represented by a pair of undivided lobes (2) lobes slightly divided (3) lobes strongly divided

\section{Adults, thorax and abdomen}

16 - Prosternal grooves for tarsomeres: (0) absent (1) present

17 - Prosternal process: $(0)$ not reaching beyond hind margin of procoxae (1) reaching beyond hind margin of procoxae

18 - Anteromedian pit of mesoventrite for reception of prosternal process: $(0)$ absent or only very shallow concavity, anteriorly delimited by rim along margin of mesoventrite (1) present (2) large hexagonal groove

19 - Propleuro-mesepisternal locking mechanism: (0) absent (1) propleural condyle and mesepisternal socket (2) mesepisternal condyle and propleural socket

20 - Shape of penultimate tarsomere: (0) not distinctly bilobed (1) distinctly bilobed

21 - Abdominal sterna: (0) abutting, not overlapping (1) tegular or overlapping

ChARACTER STATE MATRIX. For an explanation of the character coding refer to the character list above. Where a character could not be determined for a taxon it is marked as "?". Where two codes have been entered (e.g. in character 3 for Omma) both states are present in different species of the genus.

\begin{tabular}{|c|c|c|c|c|c|c|c|c|c|c|c|c|c|c|c|c|c|c|c|c|c|c|c|c|c|c|c|c|c|c|c|c|c|c|c|c|c|}
\hline & 12 & 23 & 4 & & & & & & & & & & & & & & & & & & & & & & & & & & & & & & & & & & \\
\hline ialis & 0 & $\begin{array}{ll}0 & 0\end{array}$ & 0 & o & 0 & 0 & 0 & 1 & 1 & 3 & 0 & 0 & 0 & 0 & 0 & 0 & 0 & 0 & 0 & 0 & 0 & 0 & 0 & 0 & 0 & 0 & 0 & 0 & $\begin{array}{ll}0 & 0\end{array}$ & 0 & 0 & $0 \quad 0$ & $\begin{array}{ll}0 & 0\end{array}$ & 0 & $0 \quad 0$ & 0 & 0 \\
\hline Tracl & 0 & $\begin{array}{ll}0 & 0\end{array}$ & 0 & 0 & 0 & 0 & 0 & 0 & 0 & 0 & 0 & 0 & 5 & 0 & 0 & 1 & 2 & 0 & 0 & 0 & 0 & 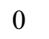 & 0 & 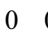 & 0 & 0 & 0 & 0 & $\begin{array}{ll}0 & 0\end{array}$ & 0 & 0 & $\begin{array}{ll}0 & 0\end{array}$ & $\begin{array}{ll}0 & 0\end{array}$ & 0 & 0 & $\begin{array}{ll}0 & 0\end{array}$ & 0 \\
\hline Micromalthus & 0 & $\begin{array}{ll}0 & 0\end{array}$ & 0 & 0 & $?$ & 1 & 2 & 0 & 3 & 4 & 2 & 4 & 4 & 0 & 0 & 0 & 0 & 0 & 0 & 1 & 1 & 1 & 1 & 1 & 1 & 1 & 1 & $\begin{array}{ll}1 & 1\end{array}$ & 11 & 0 & 1 & 10 & $\begin{array}{ll}0 & 1\end{array}$ & 1 & 11 & 11 & 1 \\
\hline Pria & 11 & 11 & 2 & 0 & 0 & 1 & 0 & 0 & 2 & 0 & 1 & 1 & 1 & 1 & 0 & 1 & 0 & 1 & 1 & 1 & 0 & 1 & 1 & 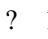 & 1 & 1 & 1 & $1 ?$ & ? ? & 0 & $?$ & $? 0$ & $\begin{array}{ll}0 & 1\end{array}$ & $?$ & 11 & $1 ?$ & $?$ \\
\hline Parc & 11 & 11 & 0 & 0 & $?$ & $?$ & 0 & 1 & 2 & 0 & 1 & 1 & 1 & 1 & 0 & 1 & 0 & 1 & 1 & 1 & $?$ & $?$ & $?$ & ? & $?$ & $?$ & ${ }^{\circ}$ & ? ? & ? ? & $?$ & ? & ? ? & $?$ & $?$ & $? ?$ & ? ? & ? \\
\hline Prolis & 11 & 11 & 4 & 2 & $?$ & $?$ & 0 & 1 & 0 & 1 & 1 & 1 & 3 & 2 & 1 & 1 & 1 & 1 & 1 & 1 & $?$ & $?$ & ? & $?$ & $?$ & $?$ & $?$ & ? ? & ? ? & $?$ & $?$ & ? ? & ? ? & $?$ & $? ?$ & ? ? & ? \\
\hline Adinolepis & 21 & 11 & 1 & 0 & $?$ & $?$ & 0 & 1 & 0 & 2 & 1 & 3 & 2 & $?$ & 1 & 1 & 1 & 1 & 1 & 1 & $?$ & $?$ & $?$ & $?$ & $?$ & $?$ & $?$ & $?$ & ? ? & $?$ & $?$ & ? ? & ? ? & $?$ & $? ?$ & ? ? & ? \\
\hline Ascic & 21 & 11 & 3 & 1 & 1 & 1 & 0 & 1 & 0 & 2 & 1 & 3 & 2 & 3 & 1 & 1 & 1 & 1 & 1 & 1 & ? & $?$ & $?$ & ? & ? & $?$ & ? & $?$ & ? ? & $?$ & $?$ & ? ? & $?$ & $?$ & $? ?$ & ? ? & ? \\
\hline Cupe & 11 & 11 & 5 & 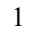 & 1 & 1 & 0 & 1 & 0 & 1 & 1 & 1 & 1 & ? & 1 & 1 & 1 & 1 & 1 & 1 & $?$ & $?$ & $?$ & ${ }^{\circ}$ & $?$ & $?$ & ? & ? ? & ? ? & $?$ & $?$ & ? ? & ? ? & $?$ & $? \quad 1$ & $1 ?$ & ? \\
\hline Tenor & 11 & 11 & 6 & 1 & $?$ & 1 & 0 & 1 & 0 & 1 & 1 & $?$ & 1 & 3 & 1 & 1 & 1 & 1 & 1 & 1 & 1 & 1 & 1 & 1 & 1 & 1 & 1 & $\begin{array}{ll}1 & 1\end{array}$ & 11 & 1 & 1 & $\begin{array}{ll}1 & 1\end{array}$ & 11 & 1 & 11 & $1 ?$ & ? ? \\
\hline Dist & 21 & $\begin{array}{ll}1 & 1\end{array}$ & 1 & 0 & $?$ & 1 & 0 & 1 & 0 & 2 & 1 & 1 & 2 & 3 & 1 & 1 & 1 & 1 & 1 & 1 & 1 & 1 & 1 & 1 & 1 & 1 & 1 & 1 & 1 & 0 & 1 & 10 & 1 & 1 & 11 & & 1 \\
\hline Rhip. & 1 & 11 & 5 & 1 & $?$ & ? & 0 & 1 & 0 & 1 & 1 & 1 & 1 & 3 & 1 & 1 & 1 & 1 & 1 & 1 & 1 & 1 & 1 & 1 & 1 & 1 & 1 & $\begin{array}{ll}1 & 1\end{array}$ & 11 & 1 & 1 & $\begin{array}{ll}1 & 1\end{array}$ & 11 & 1 & 11 & $\begin{array}{ll}1 & 1\end{array}$ & 1 \\
\hline Omma & 1 & $11 / 2$ & & 0 & $?$ & 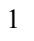 & 2 & 0 & 3 & 4 & 0 & 1 & 3 & 0 & 0 & 0 & 0 & 2 & 0 & 0 & 0 & 0 & 2 & 1 & 0 & 1 & 0 & $\begin{array}{ll}1 & 1\end{array}$ & 11 & 0 & 1 & $\begin{array}{ll}0 & 0\end{array}$ & 0 & 0 & $1 ?$ & ? ? & ? \\
\hline Tetraph & 1 & $10 / 2$ & 27 & 0 & $?$ & $?$ & 1 & 0 & 3 & 4 & 0 & 1 & 3 & 0 & 0 & 0 & 0 & 2 & 0 & 0 & ? & ? & $?$ & $?$ & ? & $?$ & ? & $?$ & ? ? & $?$ & $?$ & ? ? & ? ? & $?$ & $? ?$ & ? ? & ? \\
\hline Crowsoniella & 0 & 10 & 0 & & ? & & & & 4 & 5 & 2 & 2 & 2 & 0 & 1 & 0 & 0 & & & & ? & 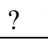 & $?$ & & $?$ & ? & $?$ & $?$ & $?$ & ? & ? & ? ? & ? & $?$ & $? ?$ & ? & ? \\
\hline
\end{tabular}




\section{Larvae, head}

22 - Head shape of second and later instars: (0) parallel-sided, slightly narrowing to the anterior, or evenly rounded (1) transverse, strongly rounded laterally, greatest width near hind margin

23 - Posteromedian emarginations of head capsule: (0) absent (1) present

24 - Endocarina of head capsule: (0) absent (1) present, undivided (2) present, forked

25 - Frontal suture of head capusle of second and later instars: (0) distinct (1) indistinct or absent

26 - Stemmata: (0) more than one pair of stemmata (1) one pair of stemmata or eyeless

27 - Length of antenna: (0) at least $20 \%$ of largest width of head capsule (1) less than $20 \%$ of largest width of head capsule

28 - Shape of distal part of mandible: (0) less than three apices (1) three apices

29 - Retinaculum: (0) present (1) absent

30 - Ligula: (0) unsclerotized (1) sclerotized, enlarged and wedge-shaped
31 - Mentum and submentum: (0) not fused (1) fused and narrowed between maxillary grooves

\section{Larvae, thorax and abdomen}

32 - Abdominal segments I-III of second and later instars: (0) shorter than thorax (1) longer than thorax

33 - Prothorax: (0) as broad as following segments (1) broader than following segments

34 - Tergal ampullae: (0) absent (1) present

35 -Ventral asperities: (0) absent (1) present

36 - Lateral longitudinal bulge of abdominal segments I-VII:

(0) absent (1) present

37 - Sclerotized process of tergum IX: (0) absent (1) present

38 - Eversible lobes of segment IX: (0) absent (1) present

39 - Segment X: (0) exposed (1) not visible externally

40 - Larval habitat: (0) not associated with wood and not endogeous (1) associated with wood

41 - Proventriculus (Beutel \& Hörnschemeyer 2002a): (0) present (1) absent

42 - Transverse muscle between gular ridges (Beutel \& Hörnschemeyer 2002a): (0) absent (1) present. 